\title{
COMPETITIVE TECHNICAL INTELLIGENCE: USING PATENT DATA TO DETERMINE SMART CITY TRENDS
}

\author{
Martin POTANČOK, Jan ČERNÝ \\ University of Economics, Prague, Czech Republic
}

\begin{abstract}
The aim of this paper is to define a method for uncovering smart city technology trends using competitive technical intelligence processes focused on intellectual property analysis using data visualisation. The authors introduce ways of gathering relevant core bibliographic data on the desired technology together with search preparation and query building. For demonstration purposes, the authors have used the European Patent Office datasets. The aim of this paper is to define a method for smart city competitive intelligence analysis focused on the main innovative companies and organizations and specific technology trends. The time period between the years 1997 and 2017 is used. Based on the results, the authors have indicated that Samsung is the leader in intelligent city innovations in this period. Five main product invention categories were also identified.
\end{abstract}

Key Words: Competitive Technical Intelligence, competitor analysis, intelligent city, patent classification.

\section{Introduction}

Competitive Technical Intelligence (CTI) is a relatively new method for monitoring external competitors' activities, with technology fields as the main focus. Although there is no specific definition for summarizing the scope of these methods, we can define it as a strategic process of company information needs for planning, collecting, analyzing and distributing data, information and knowledge entities from the external enterprise environment to monitor market activities, where technology is the common factor (Coburn 1999, Porter et al. 2007, Cerny 2016, Zhang et al. 2016).

Our paper is focused on the technology collection and analyzing phases, therefore it is important to define technology information signals as information entities where patent information is a significant part of this functional technology intelligence framework. We can distinguish the following types of information from the external environment (Brenner 2005): social media technology signals; grey literature signals; scientific information signals; joint ventures signals; intellectual property information signals; production signals; market feedback signals.

The aim of this paper is to define a method for uncovering smart city technology trends using competitive technical intelligence processes focused on intellectual property analysis. We have chosen patent information signals as a key part of intellectual property to uncover smart city technology trends with these particular topics: analyses of the key players on the global market, the country where the applicants mostly seek patent protection and the key technologies. One of the reasons for our study is also the lack of knowledge about the potential data analysis and usage of patent entities to get a competitive advantage. This fact has appeared in the study of Černý et al. (2015), which demonstrated that only $8 \%$ of Czech companies use patent information for competitive analysis. The structure of this paper corresponds to the above.

The smart city can, without question, be defined as one of the leading technology fields within our society that is presently connected to the Internet of Things (Doucek et al. 2018). Pellicer et 
al. (2013) differentiated six main fields of smart city initiatives: Smart Economy (Competitiveness), Smart Governance (Citizen Participation), Smart People (Social and Human Capital), Smart Mobility (Transport and ICT), Smart Environment (Natural Resources), Smart Living (Quality of life). They conducted state-of-the-art searches for trends through patent databases with a simple keyword set consisting of the following terms: intelligent, digital, smart, efficient, city, cities, and urban citizen. The results from 2013 showed that China is the technology leader in this field and that the main innovating activity among all companies was directed towards traffic control systems. Arasteh et al. (2016), and Nassar et al. (2018) added insights into Internet-of-Things smart city applications and through their survey pinpointed the challenges in this field. Sadowski et al. (2017) use ICT company patent profiles to design the blue ocean strategy in the field of Internet-of-Things technology, and in one part of their study also focused on smart cities. They focused on five sectors: aviation and automobile, electronics and electric manufacturing, software and computing, networking equipment and wireless equipment. These examples underline the significance of patent applications as an information source for more than just technology landscape analysis.

For the purpose of this paper, we have defined the following key intelligence questions as a part of the planning phase:

1) Which company is the market leader within the smart city sector? (KIQ1)

2) Which technology group within the smart city sector is the most innovative? (KIQ2)

3) Which technology group within the smart city sector is the most patented, and in which geographic region? (KIQ3)

\section{Patent information in the context of CTI}

As far as technology is concerned, the power of patent information lies in its complexity. The full text of a patent application tells us the names of inventors, applicants, technology details, including drawings, and, least but not last, its legal status. To see these information entities in the context with competitor analysis, we will clarify the critical elements of patent applications.

\section{Patent application structure}

Patent application is considered as one of the crucial information sources of technology content with a rich and high-quality data structure. We are commenting on individual bibliographic fields below because of the legal differences within territories, and in order to exclude the significant language similarities of specific patent application fields.

A patent application is primarily identified by the application number, or by the publication number when it is available to the public through gazettes or databases, but it also consists of other interesting metadata that provides insights into R\&D activities. A patent application should be considered as a complex information source and a competitive intelligence analyst should not avoid any part of its structure. We have summed up parts of a typical application according to WIPO (2005) and EPO (2016a) with a possible competitive intelligence context:

- $\quad$ Patent application number - The assigned number when an applicant is filing the application. Usually, it consists of a priority date (a date on which the right of priority is valid).

- $\quad$ Patent publication number - The assigned number that is created after the application was published. Usually, it consists of the date of publication and the state of the granting process.

- Title - The official title of the invention. If the applicant is aiming for a regional or international scope, it must be in a valid language (usually English is the primary 
language). The searcher should be aware of the possibility of deliberately vague or obfuscatory language due to the patent strategy of an applicant.

- $\quad$ Abstract - The basic description usually provided by the inventor. The same problem can occur regarding the vague language.

- Inventor name - Responsible persons for inventions, usually with address and other contact information.

- $\quad$ Applicant (Assignee) - The owner of the invention and of the rights for protection. It should be noted that the entity names could be indexed in different formats and characters (e.g. the subsidiary company of an applicant is still a relevant and valid information for a competitive environment analysis).

- $\quad$ Classification code - The specific notation consists of numbers and letters within a hierarchical system that classifies an invention into a particular technology set. Classifications provide a possibility to get the latest technology trend analysis. They should be also used for a cross-keyword analysis.

- $\quad$ Designated country - When seeking regional or international protection, the applicant can use specific offices, such as the European Patent Office or the World Intellectual Property Organization. Only one application form, therefore, serves as the tool for applying the protection in more countries. Country information is especially important when conducting a patent family analysis.

- Drawings - Technical drawings that uncover the structure of the invention.

- $\quad$ Claims - Novelty is one of the crucial factors leading to the granted patent and it is described in the patent claims.

- Description - A detailed description of the invention together with the methods by which an average professional can assemble it.

- $\quad$ Search Report - Patent examiners are the officers who participate in the granting process. Their search and analysis of information outputs are identified in a search report that is a required document. The collection process for this type of document is important because of the examiners' technical expertise and opinions. We should note that search reports are publicly visible before patents are granted.

- $\quad$ Reference patents - The cited patents that the inventor has used during his innovation or invention activity.

\section{Patent classifications}

Classification schemes can be considered as a powerful tool to tune our search syntax with regard to the recall or precision of results sets. On the one hand, we can easily choose the general technology fields to collect relevant records; on the other hand, we are able to determine a very specific kind of technology. In this paper, we have used the International Patent Classification (IPC) for various reasons. Firstly, it is a global classification scheme; secondly, it is being regularly updated; and finally, it could be used in every significant patent databases.

The IPC follows this structure (WIPO 2016):

Section (i.e. B)

$$
\begin{aligned}
& \text { Class (i.e. 60) } \\
& \text { Subclass (i.e. R) } \\
& \text { Main Group (i.e. 22/00) }
\end{aligned}
$$

For example, we will consider the patent application identified by the publication number WO/2017/117754 and the date of filling on 6th January 2016 with the title Traffic Light 
Management Method and System in Fire Rescue Route for Smart City. The main IPC code for this invention is G08G $1 / 087$ which can be translated as follows:

Section G Physics

Class G08 Signalling

Subclass G08G Traffic Control Systems

Main Group G08G 1/00 Traffic Control Systems for Road Vehicles

Subgroup G08G 1/087 Override of traffic control, e.g. by signal transmitted by an emergency vehicle.

We must emphasize the point that the IPC is a hierarchical system and the subgroup defined above is hierarchically under the preferred subgroup G08G 1/07 Controlling Traffic Signals.

The classification codes are also used as the tool for cross-search and for narrowing down the defined keyword set.

\section{Patent families}

Insofar, as we need to analyze the same technical content in a different number of applications with the common first filling and potential geographical validity, the patent families provide us with detailed insight. There are several patent family concepts, each operated by a different vendor, e.g. Questel Orbit, Derwent World Patent Index, Chemical Abstracts Service or INPADOC, operated by the European Patent Office. As we have used the Global Patent Index database to demonstrate our search performance in this paper, we have worked with the INPADOC concepts. There are two of these: simple patent family and extended patent family (EPO 2016b). Basically, the first concept provides, through several applications, insights into the company patent strategy regarding one invention with the same technology aspects in specific geographical territories. The extended patent family concept includes applications within the same technology field but with a wider diversity, e.g. two application have the same technology foundations but cover different inventions (Mailänder 2014), of course, with a territory analysis too.

CTI analysts use patent families for different perspectives. We can see the patent activity of a specific company in particular jurisdictions, when it updates the patent claims and other modifications of the application, and therefore effectively monitor if new art is added. Moreover, priorities may uncover the time frame of a given invention in the context of a development and production cycle.

\section{Global Patent Index}

The GPI belongs to one of the most comprehensive patent tools. As it was demonstrated in Černý (2017), this source brings unique opportunities regarding the patent landscape analysis, the legal status analysis and the detailed patent family analysis with an extensive patent data portfolio. Moreover, researchers have various search tools as standard for deep web search discovery (Table 1). To sum up, we have used the following ones:

- $\quad$ Boolean logic is represented by the AND, OR, NOT, ANDNOT operators.

- The special operator WITH narrows results when using classification schemes, INPADOC legal statuses, applicants, inventors, representatives, priorities and citations.

- Two types of proximity operators: IXw (affects the distance between two terms regardless of the orderwhere $X$ is the number), and $+X w$ where the two terms must be in the same order within a specific distance.

- $\quad$ Arithmetic operators $(=,>=,<=,<,>)$. 
GPI facts

\begin{tabular}{|c|c|}
\hline Entity & Global Patent Index \\
\hline Data Coverage & Bibliographic records \\
\hline $\begin{array}{l}\text { Number of } \\
\text { documents }\end{array}$ & $104979040^{*}$ \\
\hline Updates & Weekly \\
\hline $\begin{array}{l}\text { Geographical Data } \\
\text { Coverage }\end{array}$ & $\begin{array}{l}\text { Countries under PCT }(152)+\text { Euroasian Patent Organization + } \\
\text { European Patent Office + African Regional Intellectual Property } \\
\text { Organization }+92 \text { national offices }{ }^{*}\end{array}$ \\
\hline Search modes & Easy, Detail, Expert \\
\hline $\begin{array}{l}\text { Advanced search } \\
\text { syntax tools }\end{array}$ & Boolean, Proximity, Wildcards \\
\hline $\begin{array}{l}\text { Classification } \\
\text { systems }\end{array}$ & $\begin{array}{l}\text { IPC, CPC, US Patent Classification System, JP Classification (FI), } \\
\text { JP Classification (F-Terms) }\end{array}$ \\
\hline Legal status & INPADOC legal status codes \\
\hline $\begin{array}{l}\text { Patent family } \\
\text { information }\end{array}$ & INPADOC patent family \\
\hline $\begin{array}{l}\text { Data analysis } \\
\text { outputs }\end{array}$ & $\begin{array}{l}\text { Simple statistics: IPC, CPC, FI, F-Terms, Applicant, Cited } \\
\text { Applicant, Inventor, Publishing Office } \\
\text { Cross-reference: IPC, CPC, Inventor, Applicant, Date of Filling, } \\
\text { Date of Publication, Date of Priority }\end{array}$ \\
\hline Data visualization & Simple statistics graphs, two dimensional graphs \\
\hline Data export & $\begin{array}{l}\text { Full records in RTF, PDF, or XML format, Result lists in PDF, } \\
\text { XML, XLS or HTML, Statistics and Cross-reference graphs } \\
\text { in JSON, CSV or PDF }\end{array}$ \\
\hline
\end{tabular}

*Data by $22^{\text {th }}$ of September 2017

Source: Le Gonidec (2014), Černý 2017

- Wildcards:

* (asterisk) substitutes zero or more

\# (hash) substitutes one mandatory character

? (question mark) substitutes for one or zero character

Wildcards must not be used when phrase searching.

- $\quad$ Brackets [] are used for a date range.

- $\quad$ Parentheses () affect the order of how the logic sets will be searched.

As mentioned, the GPI framework is further analyzed in Černý (2017).

\section{Methodology}

The Smart City is a massively occurring strategic direction that helps urban areas to become more efficient in all aspects of their daily life. Cities include smart city concepts consisting of advanced ICT and knowledge ecosystem implementations in their future planning.

Almost twenty years of research and development conducted by scientists, experts and managers from different fields have created interdisciplinarity in this field that is mainly directed toward economic efficiency, safety and social welfare. The definition of smart city therefore 
tends to affect a broad spectrum of different elements. For example, Deakin and Al Waer (2011) see the four main components of the intelligent city as: "a) the application of a wide range of electronic and digital technologies to communities and cities, b) the use of information technologies to transform life and work within a region, c) the embedding of such ICTs in the city, d) the territorializing of such practices in a way that bring ICTs and people together, so as to enhance the innovation, learning, knowledge and problem solving which they offer" (Deakin and AI Waer 2011). In another point of view, Komninos (2011) defined four areas that shape the present smart city framework through applications: a) economic activities, b) city infrastructure and utilities, c) quality of life and d) city governance.

The significance of smart city initiatives underlines the growing number of research activities and published peer-review articles (Fig. 1). As we have performed a survey search in the Web of Science (WOS) database based on the occurrence of the terms "smart city" and "smart

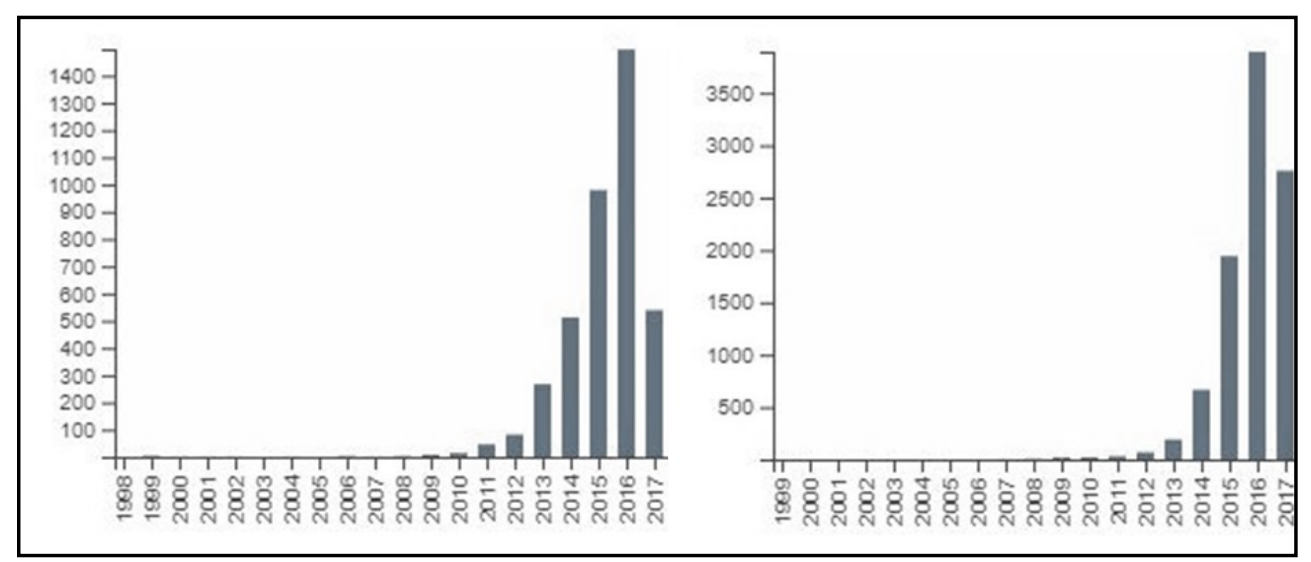

Fig. 1 - The popularity of smart city in the scientific community. The number of peer-reviewed articles and the number of citations

Source: Clarivate Analytics (2017)

Table 2

The main categories in the Web of Science database concerning the smart city topic

\begin{tabular}{|l|c|c|}
\hline \multicolumn{1}{|c|}{ Category } & Record count & \% of 3961 \\
\hline Engineering Electrical Electronic & 1274 & $32.164 \%$ \\
\hline Computer Science Information Systems & 922 & $23.277 \%$ \\
\hline Computer Science Theory Methods & 821 & $20.727 \%$ \\
\hline Telecommunications & 722 & $18.228 \%$ \\
\hline Computer Science Interdisciplinary Applications & 414 & $10.452 \%$ \\
\hline Computer Science Hardware Architecture & 350 & $8.836 \%$ \\
\hline Computer Science Artificial Intelligence & 329 & $8.306 \%$ \\
\hline Computer Science Software Engineering & 238 & $6.009 \%$ \\
\hline Green Sustainable Science Technology & 213 & $5.377 \%$ \\
\hline Urban Studies & 212 & $5.352 \%$ \\
\hline
\end{tabular}

Source: Clarivate Analytics (2017) 
cities" in the title, abstract or keyword sections, we see in Table 2 the following main scientific streams through the Web of Science research categories in a set of 3961 results. As we have analyzed the smart city field from scientific perspectives, we will compare it with the market insights derived from the patent information.

\section{Methods of analysis}

Before any search is made, it is necessary to establish a relevant keyword set with an emphasis on recall. Two approaches to get the keywords have been chosen: a) the IEEE thesaurus analysis (IEEE 2017), b) the term tactics (Bates 1979), and they were put it into the following structure (Table 3). Bates's term tactics (1979) are providing different approaches on

\section{Keywords analysis}

Table 3

\begin{tabular}{|l|l|}
\hline \multicolumn{1}{|c|}{ Central terms } & \multicolumn{1}{c|}{ Smart city } \\
\hline Superordinate terms & City, town, metropolitan, urban area \\
\hline Related terms & $\begin{array}{l}\text { Smart grids, internet of things, urban informatics, smart public } \\
\text { health, smart community, smart government, smart energy, smart } \\
\text { structures, intelligent structures }\end{array}$ \\
\hline Synonymous terms & Intelligent city, digital city, virtual city \\
\hline Specific terms & $\begin{array}{l}\text { Wireless water meters, smart waste management, smart lighting, } \\
\text { smart building, smart transportation, smart transportation system, } \\
\text { intelligent vehicle, intelligent transportation, intelligent transporta- } \\
\text { tion system, water quality monitoring, smart car }\end{array}$ \\
\hline
\end{tabular}

Source: own research

how the searcher could analyse the possible relevant keywords for particular searches and use them with specific relevant search tactics. Bates's term and search tactics concept was firstly introduced at the end of the 1970s, when a complex database vendor infrastructure existed in the United States. Information overload was an emerging topic not only within the academic community and these methods significantly ensured its reduction. Moreover, they are still valid for the contemporary information environment.

\section{Performing a patent search}

We have chosen two search strategies. The first is focused on the recall of results and we have used a Boolean logic approach with the following syntax:

WORD = ((city OR cities OR town* OR metropolitan OR urban) AND ((city AND (smart OR intelligent OR digital OR virtual)) OR ("smart grid*" OR "internet of things" OR IoT OR "urban informatics" OR "smart public health" OR "smart communit*" OR "smart government*" OR "smart energy" OR "smart structure*" OR "intelligent structure*") OR ("wireless water" OR "smart waste management" OR "smart lighting" OR "smart building*" OR "smart transportation" OR "intelligent vehicle*" OR "intelligent transportation" OR "smart vehicle*" OR "smart car*"))

The field operator WORD performs searches within all text fields of a patent application. The result set contains 4056 patent documents in 3089 patent families.

The second search strategy leverages the precision. We have edited our syntax and used the proximity operator /10w in the syntax. Then each of the terms in the first logical group is being searched within 10 words of the second logical group: 
WORD = ((city OR cities OR town* OR metropolitan OR urban) /10w ("smart city" OR "intelligent city" OR "digital city" OR "smart grid*" OR "internet of things" OR loT OR "urban informatics" OR "smart public health" OR "smart community*" OR "smart government" OR "smart energy" OR "smart structure*" OR "intelligent structure*" OR "wireless water" OR "smart waste management" OR "smart lighting" OR "smart building*" OR "smart transportation" OR "intelligent vehicle*" OR "intelligent transportation" OR "smart vehicle*" OR "smart car*"))

The result set contains 1340 patent documents in 888 patent families.

\section{Results and Discussion}

For the purposes of this paper, we will work with the first broader set of documents to discover trends within the smart city field, together with the key players, and to carry out a specific technology analysis to demonstrate the patent information entity role in the competitive intelligence process. When considering the planning phase, we first needed to define key intelligence questions directed towards the smart city field and to chose the particular patent index - in our case, the Global Patent Index that also provided international intellectual property context from bibliographic fields. The essential part of this phase is to carry out the keyword analysis and to prepare for the collection phase. The IEEE thesaurus has provided us with the relevant expert terms that are valid for this industry field and which are broadly used in the scientitific, research and technical literature. From our point of view, the thesaurus is neccessary when considering the relation between the search precision and recall. However, we are aware of the possible missing relevant hits so that the keyword analysis and preparation from unstructured texts is inevitable, so we have used Bates' search tactics, especially the term tactics and trace search tactics. Although Bates defined these tactics in the 1970s, they are still valid and very effective for keyword preparation. The collection within a patent sector can be performed on a national, regional or international level. We needed to consider which source was the most relevant for the purposes of our paper. The Global Patent Index, operated by the European Patent Office, is an up-to-date and well-structured source that provides significant insights based on complex keyword preparations including value-added Asian translation content fields. We were able to perform different patent search types within a global perspective and to get valuable business insights in the smart city field.

The Competitive Intelligence patent analysis phase starts with Table 4 (including the first ten companies and institutions) and it uncovers that Samsung is the leader within the smart city technology innovation activities in the recent years. The distribution over time (2015-2017)

\section{Key player analysis}

\begin{tabular}{|l|c|}
\hline \multicolumn{1}{|c|}{ Applicant } & Number of patent applications \\
\hline Samsung Electronics Co Ltd & 354 \\
\hline Chengdu Qinchuan Tech Dev Co & 25 \\
\hline State Grid Corp China & 23 \\
\hline Shenzhen Shuangchuang Tech Dev Co Ltd & 23 \\
\hline Univ Wuhan & 16 \\
\hline Univ Southeast & 15 \\
\hline Univ Shanghai Jiaotong & 10 \\
\hline Univ Beijing Technology & 10 \\
\hline Feng Xuanyu & 10 \\
\hline Cai Jinhong & 10 \\
\hline
\end{tabular}

Source: Le Gonidec (2014) 
shows a growing trend (Fig. 2). We are also able to specify where companies seek patent protection mostly by pinpointing the publishing offices (Table 5). An example of visualizing this

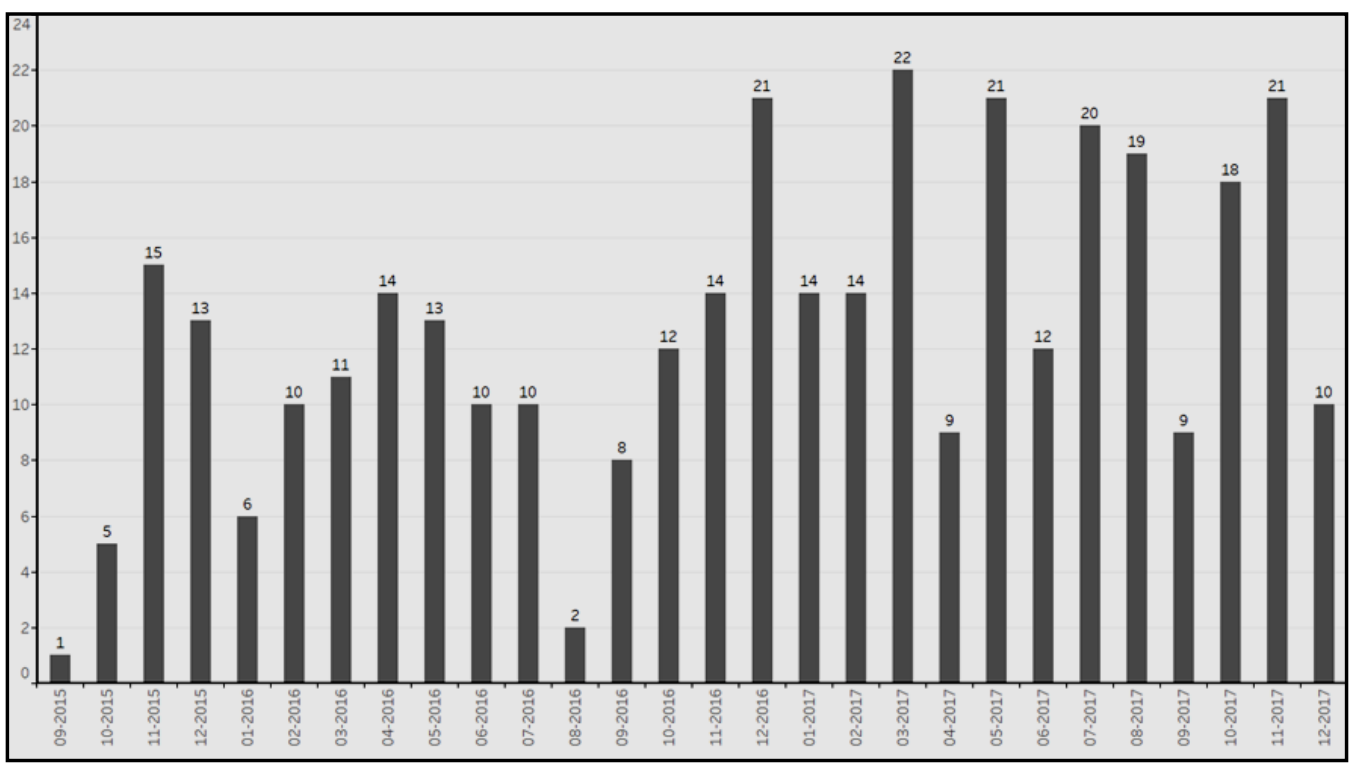

Fig. 2 - Patent activity of Samsung between 2015 and 2017

Source: own research based on Le Gonidec (2014)

Table 5

Publishing Offices analysis

\begin{tabular}{|l|c|}
\hline \multicolumn{1}{|c|}{ Publishing Office } & $\begin{array}{c}\text { Number of patent } \\
\text { applications }\end{array}$ \\
\hline China & 2357 \\
\hline WIPO (152 PCT countries) & 218 \\
\hline United States & 164 \\
\hline Republic of Korea & 153 \\
\hline Japan & 84 \\
\hline EPO (EU countries) & 34 \\
\hline Great Britain & 21 \\
\hline Taiwan & 16 \\
\hline Germany & 14 \\
\hline Russia & 8 \\
\hline Canada & 8 \\
\hline France & 3 \\
\hline Australia & 3 \\
\hline India & 2 \\
\hline Slovakia & 1 \\
\hline Netherland & 1 \\
\hline Mexico & 1 \\
\hline Greece & 1 \\
\hline
\end{tabular}

Source: Le Gonidec (2014) 


\section{Martin POTANČOK, Jan ČERNÝ}

data for Samsung is available in Fig. 3. Based on the map, it is possible to identify the countries and regions where the companies seek patent protection (in this case, Samsung). This map can be interactive and shared to support further analysis (Datig and Whiting 2018).

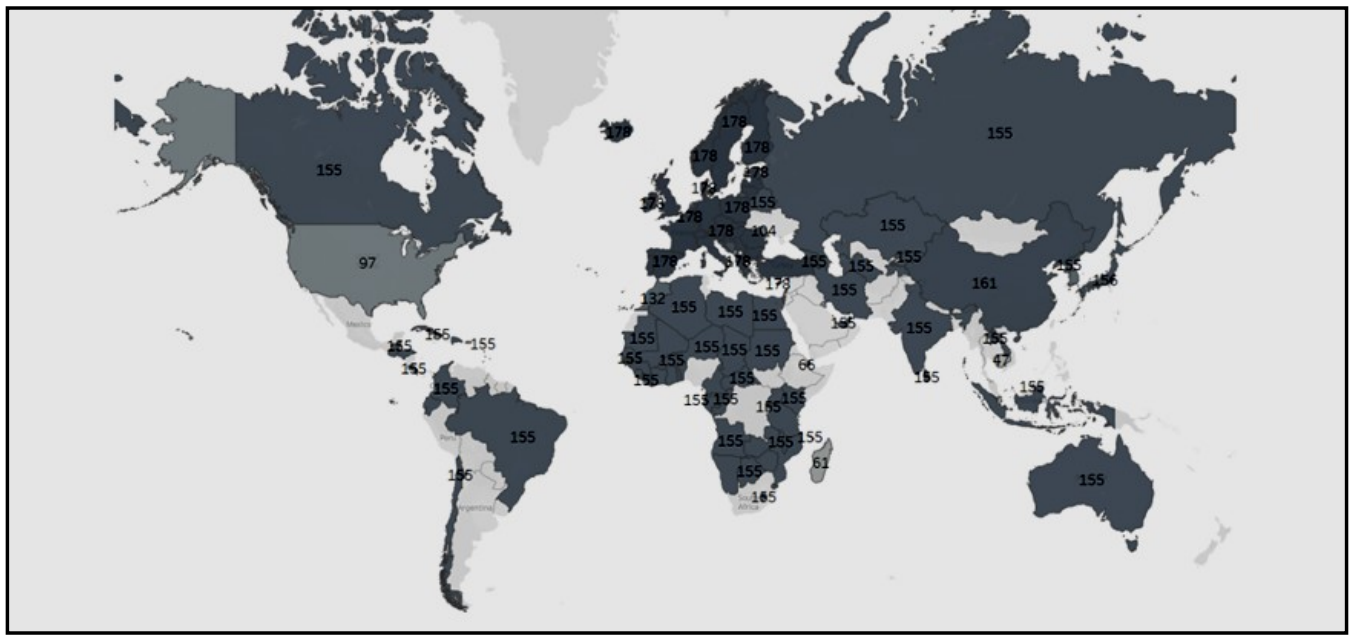

Fig. 3 - Patent activity of Samsung between 2015 and 2017 Source: own research based on Le Gonidec (2014)

If we use the primary IPC subgroup codes of the given patent applications, we can mine the information about technology directions in detailed definitions. In the following table (Table 6),

Technology analysis

Table 6

\begin{tabular}{|l|l|c|}
\hline \multicolumn{1}{|c|}{$\begin{array}{c}\text { IPC code } \\
\text { (subgroup) }\end{array}$} & \multicolumn{1}{|c|}{ Definition } & $\begin{array}{c}\text { Number of patent } \\
\text { applications }\end{array}$ \\
\hline H04L29/08 & $\begin{array}{l}\text { Transmission control procedure, e.g. data link level } \\
\text { control procedure }\end{array}$ & 233 \\
\hline H05B37/02 & $\begin{array}{l}\text { Controlling (in the main group Circuit } \\
\text { arrangements for electric light sources in general) }\end{array}$ & 160 \\
\hline G06F17/30 & $\begin{array}{l}\text { Information retrieval; Database structures } \\
\text { therefore }\end{array}$ & 126 \\
\hline G06Q50/26 & $\begin{array}{l}\text { Government or public services (in the main group } \\
\text { Systems or methods specially adapted for a } \\
\text { specific business sector, e.g. utilities or tourism) }\end{array}$ & 115 \\
\hline H04N7/18 & $\begin{array}{l}\text { Closed-circuit television systems, i.e. systems in } \\
\text { which the signal is not broadcast }\end{array}$ & 102 \\
\hline
\end{tabular}

Source: Le Gonidec (2014)

we have provided a technology insight with five particular technical solutions.

We have analyzed the patent activity going back 20 years (Fig. 4) and, as we can see, the patenting activity was more frequent than the peer-reviewed research. The Competitive 
Intelligence distribution phase leads to two main conclusions: firstly, Samsung owns a major part of the intellectual property rights with the smart city sector; secondly, from its protection strategy, we can assume that it possibly controls and will control the smart city market. Our results also confirmed a strong Chinese intellectual property strategy on a national level that has been visible for several years. It could be estimated that the future smart city patented technology will be constantly produced by and exported from China.

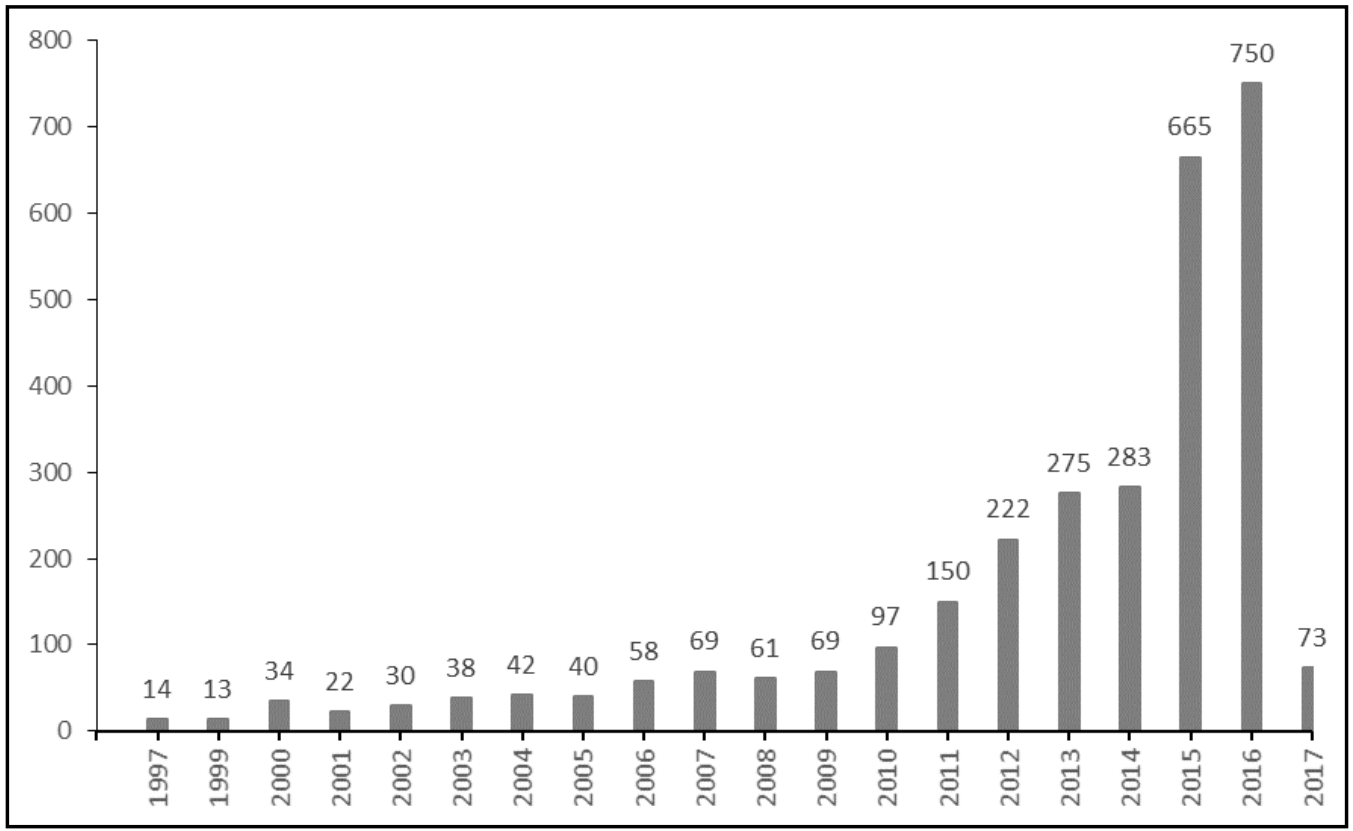

Fig. 4- Patent activity of Samsung between 1997 and 2017 Source: own research based on Le Gonidec (2014)

\section{Conclusions}

This paper has described the use of patent information as one of the technology intelligence signals in the smart city field. Our aim has been to provide methods for uncovering innovation activities, determining key players on the market and the main technology concepts in this area. The recommended set of analyses, including their visualization, is also part of the output. The structure of the patent information is discussed in the first part of the paper, together with the patent classification and patent family importance.

The authors have prepared a keyword set through the analysis of the IEEE thesaurus and by using the information term tactics. The search for desired data has been conducted in the Global Patent Index with two approaches, one directed towards the broader relevant result set and one towards the set with the emphasis on precision.

To conclude, we have answered all of our defined key intelligence questions. Firstly, the role of Samsung can be presented as the long-term market leader in smart city technologies and that most inventions have been published in the past three years (KIQ1). Secondly, based on the Web of Science data, we can assume that the engineering electrical electronics belongs to the 
most researched category (KIQ2). Finally, the transmission control procedure, e.g. the data link level control procedure, is the most patented technology group (KIQ3).

Based on our former research considering the significant underestimation of patent information entities, our results provide a detailed method on how to gather relevant technology data and information, to put them into context and to get significant business insights in terms of the competitive technical intelligence process. We have shown the ability to use patent information as one of the most important key player activity sources focused on a specific detailed technology with further indications of a business early warning system within a specific business sector. Concurrently, this intelligence process could be also used as a strategic planning support, or a support for a patent strategy model. The setup of analytical services should be covered within further research.

\section{Acknowledgements}

This paper was written thanks to the long-term institutional support of research activities by the Faculty of Informatics and Statistics, University of Economics, Prague. We also would like to thank Dr. James Partridge for his academic support.

\section{References}

ARASTEH H., HOSSEINNEZHAD V., LOIA V., TOMMASETTI A., TROISI O., SHAFIEKHAH M., SIANO P. (2016), lot-based smart cities: A survey, 2016 IEEE 16th International Conference on Environment and Electrical Engineering (EEEIC), 1-6.

BATES M. J. (1979), Information search tactics, Journal of the American Society for Information Science 30 (4), 205-214.

BRENNER M. (2005), Technology Intelligence at Air Products: Leveraging Analysis and Collection Techniques, Competitive Intelligence Magazine 8 (3), 6-19.

ČERNÝ J., MOLNÁR Z., HAWLOVÁ K. (2015), Průzkum využívání informačních zdrojů pro Competitive Intelligence $v$ českých firmách, Systémová integrace 22 (3), 81-90.

CERNY J. (2016), Information Needs in Competitive Technical Intelligence, Journal of Systems Integration 7 (1), 3-12.

ČERNÝ J. (2017), Using the International Patent Classification System in Competitive Technical Intelligence, SBORNIK, 16-26.

COBURN M. M. (1999), Competitive Technical Intelligence: A Guide to Design, Analysis, and Action, American Chemical Society, New York.

DATIG I., WHITING P. (2018), Telling your library story: tableau public for data visualization, Library Hi Tech News 35 (4), 6-8.

DEAKIN M., AL WAER H. (2011), From intelligent to smart cities, Intelligent Buildings International 3 (3), 133-139.

DOUCEK P., PAVLICEK A., LUC L. (2018), Internet of Things or Surveillance of Things?, 11th International Conference on Research and Practical Issues of Enterprise Information Systems (CONFENIS) 2017, 45-55.

EPO (2016a), Patent information services for experts, Retrieved from: www.epo.org.

EPO (2016b), EPO worldwide legal status database (INPADOC), Retrieved from: www.epo.org.

KOMNINOS N. (2011), Intelligent cities: Variable geometries of spatial intelligence, Intelligent Buildings International 3 (3), 172-188.

IEEE (2017), 2017 IEEE Thesaurus, Retrieved from: www.ieee.org.

LE GONIDEC P. (2014), Global Patent Index - GPI, European Patent Office, Retrieved from: www.epo.org

MAILÄNDER L. (2014), Topic 3 - Exercises on patent families, Retrieved from: www.wipo.int. 
NASSAR A. S., MONTASSER A. H., ABDELBAKI N. (2018), A Survey on Smart Cities' IOT, Proceedings of the International Conference on Advanced Intelligent Systems and Informatics 2017, 855-864.

PELLICER S., SANTA G., BLEDA A. L., MAESTRE R., JARA A. J., SKARMETA A. G. (2013), A Global Perspective of Smart Cities: A Survey, 2013 Seventh International Conference on Innovative Mobile and Internet Services in Ubiquitous Computing, 439-444.

PORTER A. L., SCHOENECK D. J., FREY P. R., HICKS D. M., LIBAERS D. P. (2007), Mining the Internet for Competitive Technical Intelligence, Competitive Intelligence Magazine 10 (5), 24-28.

SADOWSKI B. M., WHALLEY J., NOMALER Ö. (2017), Technological Diversification into 'Blue Oceans'? A patent-based analysis of patent profiles of ICT Firms, SSRN, 1-27.

WIPO (2005), Handbook on industrial property information and documentation, Retrieved from: www.wipo.int. WIPO (2016), IPC Internet Publication Help, Retrieved from: www.wipo.int.

ZHANG Y., ROBINSON D. K. R., PORTER A. L., ZHU D., ZHANG G., LU J. (2016), Technology roadmapping for competitive technical intelligence, Technological Forecasting and Social Change 110, 175-186.

Initial submission: 08.07.2019

Revised submission: 19.01.2020

Final acceptance: 07.02.2020

Correspondence: Department of Information Technology, Faculty of Informatics and Statistics, University of Economics, nám. W. Churchilla 1938/4, 13067 Prague 3 - Žižkov, Czech Republic.

Email: martin.potancok@vse.cz 
